\title{
Pensamento pós-colonial, gênero e Poder em MARÍA LUgONES: MULTIPLICIDADE ONTOLÓGICA E MULTICULTURALISMO
}

\author{
Guilherme Paiva de Carvalho ${ }^{1}$
}

Resumo: $\mathrm{O}$ artigo objetiva refletir sobre as concepçóes de gênero, poder, multiplicidade e multiculturalismo, em María Lugones, analisando o modo como sua teoria se associa ao pensamento pós-colonial. Para tanto, aborda a perspectiva do pensamento pós-colonial e a noçáo de colonialidade do poder, considerando o sistema moderno/colonial de gênero. As teorias pós-coloniais criticam o paradigma epistemológico do Ocidente e a hierarquização baseada na distinção entre humanos e não humanos, colonizador e colonizado. Em sua análise do sistema moderno/colonial, María Lugones introduz a ideia de gênero na reflexão acerca das relaçôes de poder. A teoria de Oyèronké Oyěwùmí é uma referência para María Lugones, que desenvolve uma concepção de intersecção de raça, classe, gênero e sexualidade, propondo um feminismo decolonial baseado na identificaçáo de formas de resistência e coalizão para emancipação.

Palavras-chave: Gênero. Poder. Colonialismo. Multiculturalismo.

\section{INTRODUÇÁO}

Em julho de 2020, morreu nos Estados Unidos a filósofa argentina e ativista feminista María Lugones. Além de escritos relevantes para especificidade e originalidade do pensamento filosófico latino-americano, principalmente

\footnotetext{
${ }^{1}$ Pós-Doutor em Ciências Sociais pelo Centro Interdisciplinar de Ciências Sociais da Universidade de Évora (UÉvora), Évora - Portugal. Professor Permanente do Programa de Pós-Graduação em Ensino (UERN/UFERSA/IFRN), do Programa de Pós-Graduação em Ciências Sociais e Humanas e Professor Colaborador do Programa Interinstitucional de Pós-Graduação em Ensino de Filosofia da Universidade do Estado do Rio Grande do Norte (UERN), Mossoró. RN - Brasil. (D) https://orcid. org/0000-0002-1165-5761. E-mail: guimepaivacarvalho@gmail.com.
}

https://doi.org/10.1590/0101-3173.2022.v45esp.16.p311 
no tocante a questôes de gênero, colonialismo, colonialidade e poder, María Lugones é uma referência para o movimento feminista pós-colonial.

De acordo com Luciana Ballestrin (2013), o termo "pós-colonialismo" está associado tanto ao contexto histórico da descolonização quanto aos estudos culturais desenvolvidos por cientistas sociais, nos Estados Unidos e na Inglaterra. Ballestrin (2013) menciona a perspectiva de Frantz Fanon como precursora das teorias pós-coloniais, além de destacar a importância do poeta Aimé Césaire (1913-2008) e do escritor Albert Memmi (1920-2020).

$\mathrm{Na}$ América Latina, o pensamento pós-colonial é radicalizado pelo Grupo Modernidade/Colonialidade (M/C), que se diferencia dos estudos culturais, ao dar ênfase para a proposta de descolonização, ou "decolonização" epistemológica $^{2}$ (BALLESTRIN, 2013). No presente artigo, será utilizada a expressão "pensamento pós-colonial"3 para enfatizar a radicalização da crítica ao eurocentrismo e renovaçáo epistêmica nas ciências sociais sugerida pela teoria da colonialidade, abrangendo as suas referências teóricas e a ideia de descolonização epistemológica.

Entre as abordagens do pensamento pós-colonial, Maldonado Torres (2017) cita a teoria de Frantz Fanon sobre os reflexos dos processos de colonizaçáo nas subjetividades. No entanto, apesar de introduzir a temática de gênero, Fanon (2008) aborda a situação do homem colonizado. Outras teorias pós-coloniais dedicaram-se a discutir a dicotomia entre civilizaçáo e barbárie (ZEA, 2005), sem mencionar as formas de opressão associadas ao gênero e à sexualidade. Assim, são suscitados os seguintes questionamentos: qual a importância das relaçóes de gênero, na análise da colonização? Em que sentido uma visão dicotômica da relação de poder entre colonizado e colonizador reduz a complexidade dos processos coloniais a um paradigma epistemológico maniqueísta, baseado no discurso eurocêntrico?

$\mathrm{Na}$ análise das sociedades pós-coloniais, Lugones $(2007,2008)$ inclui as relaçóes de gênero. Em sua perspectiva teórica, é destacada a intersecção

\footnotetext{
2 Ballestrin (2013) menciona a sugestão de Catherine Walsh de utilizar o termo "decolonizaçáo", em vez de "descolonização", para distinguir a perspectiva do Grupo Modernidade/Colonialidade, baseada na centralidade das sociedades latino-americanas e na crítica ao eurocentrismo e ao colonialismo epistemológico, ontológico e político que permanece nas sociedades colonizadas.

${ }^{3}$ Luciana Ballestrin (2013, p. 91) afirma que "[...] o argumento pós-colonial em toda a sua amplitude histórica, temporal, geográfica e disciplinar percebeu a diferença colonial e intercedeu pelo colonizado.” Há um comprometimento com o propósito de superar as relaçốes de dominação resultantes do colonialismo.
} 
entre as categorias conceituais de raça ${ }^{4}$, classe, gênero e sexualidade. A inclusão da ideia de intersecção entre as categorias de gênero, classe e raça, no debate em torno do colonialismo, sugere mudanças no paradigma do pensamento pós-colonial. Outro aspecto importante de sua teoria diz respeito à concepção hierárquica desenvolvida pela epistemologia ocidental, a qual diferencia o humano e o não humano. Na visão de Lugones (2011, p. 106), “[...] a hierarquia dicotômica entre o humano e o não humano" é considerada como um eixo epistemológico "[...] central da modernidade colonial."

Além do seu comprometimento com o movimento feminista nos Estados Unidos e na América Latina, sobretudo na defesa de mulheres indígenas norte-americanas, latino-americanas e africanas, o pensamento de María Lugones apresenta propostas de mudança de paradigma para a teoria pós-colonial. Polêmicas e debates em torno de sua perspectiva acerca das concepçôes de colonialismo e gênero suscitaram críticas, controvérsias e questionamentos, no campo epistemológico das Ciências Humanas e Sociais (BALLESTRIN, 2017; SEGATO, 2012). Ademais, Lugones (2007, 2008) critica o modelo ontológico-maniqueísta, binário e dicotômico do sistema colonial/moderno "[...] com a referência à produçáo de gênero" (MALDONADO-TORRES, 2017, p. 123). No pensamento de Lugones (2003), a noção de dupla consciência propicia o reconhecimento ontológico da multiplicidade.

Como destaca Walter Mignolo (2014, p. 9), a "colonialidade do ser e do saber" apresenta níveis que incluem o controle econômico, com a "apropriação de terras e recursos naturais", o "controle da autoridade" por

\footnotetext{
${ }^{4}$ De acordo com Aníbal Quijano (2000, p. 122), "[...] a classificação social da população mundial" baseada na "ideia de raça" consiste em "uma construçấo mental que expressa a experiência básica da dominaçấo colonial”, relacionada com o exercício do poder em um nível global e com a racionalidade eurocêntrica dominante. Assim, a "raça" pode ser entendida como um modo de classificação de pessoas e grupos sociais, constituindo uma forma de dominação. "As diferenças fenotípicas entre vencedores e vencidos foram usadas como justificação da produção da categoria 'raça', embora se trate, antes do mais, de uma elaboração das relaçóes de dominação como tais." (QUIJANO, p. 106). Fernando Coronil (2000, p. 56) sugere que "[...] a noção espanhola de "pureza de sangue"” estabeleceu "nas Américas as distinçôes entre raças superiores e inferiores." Essas distinções tomaram como referência concepçôes biológicas, tomando determinados povos e etnias europeias como superiores. A antropóloga e historiadora Lília Schwarcz (1993) analisa as teorias raciais formuladas por Buffon (1707-1788), Cornelius de Pauw (1739-1799), Arthur Gobineau (1816-1882), dentre outros, mostrando a recepção dessas concepçôes, no Brasil. Kabengele Munanga (1999) salienta que os intelectuais da primeira República no Brasil, baseando-se nas teorias raciais, consideravam que as pessoas não brancas - incluindo os povos indígenas e africanos, assim como os grupos étnicos mestiços - eram seres inferiores. Schwarcz (2013, p. 35) afirma que a noção de "raça" consiste em "[...] uma construçẫo histórica e social [...]"
} 
meio de organizaçóes políticas governamentais, o "controle de gênero e sexualidade" - demonstrado por Lugones e Tlostanova (2014) - e o "controle do conhecimento e da subjetividade". Desse modo, as relações de gênero constituem um dos níveis da "colonialidade do poder". Ao abordar o conceito de colonialidade, Aníbal Quijano (2014, p. 285) ressalta que se trata de um padrão de poder surgido com a modernidade, sendo "[...] mais profundo e duradouro que o colonialismo.” De acordo com Mignolo (2014), Lugones trata da colonialidade do saber e do ser, a partir das categorias de gênero e sexualidade.

A colonialidade do poder imporia a categorização, a hierarquização e a inferiorização de determinados indivíduos e grupos étnicos. Contudo, há formas de resistência à opressão. Para tanto, é necessária uma descolonização das formas de produção do saber e dos modos de subjetivaçáo opressores. Além de incluir as relações de gênero e a intersecção com as categorizações de "raça", classe e sexualidade, a teoria de Lugones (2014) enfatiza as resistências ao poder e a descolonizaçáo das subjetividades.

O presente artigo propóe refletir sobre a inserção da perspectiva de Lugones no pensamento pós-colonial, dando destaque às concepçóes de gênero e poder como elementos ontológicos de sociedades colonizadas. Para tanto, o estudo subdivide-se em quatro partes. Na primeira, é abordado o pensamento pós-colonial, com ênfase para as críticas suscitadas por Lugones. A segunda parte examina a concepção de colonialidade de gênero e poder, bem como questôes epistemológicas suscitadas pela teoria da filósofa argentina. Para ressaltar os referenciais teóricos que subsidiam a análise epistemológica do sistema colonial de gênero desenvolvida por Lugones, a terceira parte apresenta a teoria de gênero de Oyèronké Oyěwùmí, enfatizando críticas em torno da perspectiva das duas autoras. Na última parte, propôe-se uma reflexão sobre as limitaçóes metodológicas e contribuiçôes da teoria de Lugones para o pensamento pós-colonial, a partir dos conceitos de multiplicidade ontológica e multiculturalismo ${ }^{5}$ radical.

\footnotetext{
${ }^{5}$ Como evidenciamos em outro estudo, o conceito de multiculturalismo é associado a "[...] exigências políticas de reconhecimento das identidades culturais." (CARVALHO; SILVA, 2015, p. 143). Kabengele Munanga (2010, p. 36) concebe o multiculturalismo "[...] como encontro de culturas, ou seja, a existência de conjuntos culturais fortemente constituídos, cuja identidade, especificidade e lógica internas devem ser reconhecidas [...]". Vera Candau (2012) estabelece uma distinçấo entre o multiculturalismo assimilacionista, o multiculturalismo diferencialista e o multiculturalismo interativo. $\mathrm{Na}$ filosofia política, Charles Taylor (1998, p. 56) aborda o multiculturalismo como "reconhecimento igualitário" em sociedades democráticas, tomando como referência a perspectiva de Hegel. Nos estudos culturais, Stuart Hall (2003, p. 52) relaciona o multiculturalismo com “[...] estratégias e políticas
} 


\section{Pensamento pós-Colonial, descolonizaçấo e eurocentrismo}

O pensamento pós-colonial propicia uma reflexão acerca das relaçóes de poder que constituem a modernidade, ao suscitar críticas ao paradigma da filosofia ocidental. Essas críticas são direcionadas, sobretudo, à universalização do sujeito epistêmico como símbolo de ser humano e do paradigma epistemológico do Ocidente como modelo de produção do conhecimento. A universalização do sujeito epistêmico e do paradigma epistemológico do Ocidente realiza-se por meio de relaçóes complexas e assimétricas de poder, as quais impóem o silenciamento e a invisibilidade de saberes e da multiculturalidade de grupos étnicos e sociedades inferiorizadas e subalternizadas.

Em discursos literários e filosóficos, a origem da civilização europeia é relacionada com a Grécia antiga e o Império romano. Segundo Enrique Dussel (2000), a Europa moderna se constitui como uma invenção do romantismo alemão do final do século XVIII. Regióes da Ásia e da África — onde se localizam atualmente a Turquia e o Egito - possuíam culturas mais desenvolvidas do que a grega, no período clássico. Assim, o mito da modernidade e a ideia de civilização associada à cultura ocidental - construída com base em discursos filosóficos e literários que sustentaram a originalidade e a continuidade histórica entre o mundo greco-romano, o cristianismo e a Europa moderna — são invenções ideológicas eurocêntricas "[...] do final do século XVIII romântico alemão.” (DUSSEL, 2000, p. 24).

Desse modo, a noção de humanidade e a condição de ser humano são concebidas por meio de discursos e práticas institucionalizadas que se refletem em padrôes normativos de comportamento e formas de exclusão. Como construção discursiva da epistemologia ocidental, a concepção de humanidade corresponde a um eurocentrismo ${ }^{6}$, ou ao discurso hegemônico no Ocidente,

adotadas para governar e administrar problemas de diversidade e multiplicidade gerados pelas sociedades multiculturais." Wieviorka (1999) reflete sobre as limitaçōes do multiculturalismo como política de reconhecimento da diversidade cultural. Ao sugerir uma radicalização do multiculturalismo, María Lugones (2014b) questiona a perspectiva multicultural ornamental, dando ênfase para as múltiplas formas de opressão, as resistências às relaçóes de poder, a crítica ao eurocentrismo e a proposta de emancipação do feminismo descolonial.

${ }^{6}$ Como destaca Edward Said (1990, p. 19), a identidade cultural europeia se coloca como "[...] superior em comparação com todos os povos e culturas năo-europeus." Dessa maneira, o eurocentrismo baseiase em uma ideia de superioridade da cultura europeia em comparaçáo com outras culturas. Samir Amin (1989, p. 75) sugere que o eurocentrismo "[...] implica em uma teoria da história universal" e, por conseguinte, em "um projeto político mundial" relacionado com o "modo capitalista de organizaçáo" da sociedade. 
que constitui subjetividades ao inserir-se em bases ontológicas, históricas e epistemológicas das sociedades colonizadas.

De acordo com Maldonado-Torres (2017), a crítica ao paradigma epistemológico do Ocidente, suscitada pelos estudos da descolonização, tiveram as contribuiçóes de Césaire e Frantz Fanon. Na obra Pele negra, máscaras brancas, Fanon (2008) aborda a relação entre o indivíduo colonizado e a metrópole. A colonização impóe um processo de interiorização da inferioridade nas subjetividades das pessoas colonizadas. A partir de relaçóes de opressão, os povos colonizados interiorizam um complexo de inferioridade em decorrência do "sepultamento de sua originalidade cultural" (FANON, 2008, p. 34). O indivíduo colonizado assimila os valores da metrópole, considerando-os como superiores. A concepção de inferioridade é construída pelo seu correlato, ou seja, por intermédio da afirmação da ideia de superioridade da cultura europeia.

No processo de colonização, as relaçôes de dominação resultam na formação de um complexo de inferioridade nos indivíduos, à medida que o discurso hegemônico europeu contesta a humanidade dos povos colonizados. Para ser reconhecido como humano, o indivíduo colonizado precisa incorporar os valores culturais dos grupos hegemônicos da metrópole, buscando assemelhar-se ao colonizador. A filosofia europeia, a qual se considera originária da Grécia Antiga, se coloca como critério de avaliação de saberes, definindo a si própria como discurso de verdade. Nesse sentido, “[...] o eurocentrismo e a colonialidade são elementos chave para o entendimento da ideia de que a filosofia é uma 'versão' do pensamento humano exclusivamente europeia." (NOGUERA, 2014, p. 30).

A formação da consciência e a constituição de um complexo de inferioridade, nos sujeitos e nas geraçóes que vivenciam processos de colonização, caracterizam a colonialidade como um processo que perdura após o período colonial (QUIJANO, 2014). O modo de dominação dos povos europeus na colonização realizou um processo de formação do complexo de inferioridade, à medida que se contesta a humanidade do indivíduo colonizado. Fanon (2008, p. 94) descreve da seguinte forma o complexo de inferioridade associado ao racismo, a práticas de discriminação e colonização:

[...] começo a sofrer por náo ser branco à medida que o homem branco me impóe uma discriminação, faz de mim um colonizado, me extirpa qualquer valor, qualquer originalidade, pretende que seja um parasita no mundo, que é preciso que eu acompanhe o mais rápido possível o mundo branco [...] (FANON, 2008, p. 94). 
Em vista disso, os povos colonizados tendem a agir e pensar de acordo com os valores culturais da metrópole, para que seja reconhecida a sua humanidade. A condição de ser humano é sustentada pelo indivíduo colonizador. Leopoldo Zea (2005) se ampara em Frantz Fanon para abordar o processo de colonização e supervalorização da cultura europeia, na América Latina. A Europa, no processo de conquista ${ }^{7}$ de outros continentes, se definiu “[...] como centro do mundo." (ZEA, 2005, p. 24).

Com um olhar de superioridade, grupos hegemônicos europeus se dirigiram a pessoas, comunidades e sociedades, considerando que a condição de ser humano correspondia somente ao modo de ser do Ocidente. Os outros apenas se assemelhavam a eles. As comunidades indígenas eram vistas como subumanas, bem como os povos africanos escravizados e os grupos étnicos mestiços e orientais. As populaçóes formadas pela mestiçagem eram vistas como uma forma de degeneração da cultura europeia. Observa-se uma dicotomia entre civilização e barbárie, além de relaçôes de poder e dependência entre povos dominantes e povos colonizados.

Para compreender a psicologia dos povos colonizados, Fanon (2008) analisa o processo de colonização. Nos discursos da colonização distinguemse civilizados e selvagens. Os povos colonizados são considerados selvagens. Somente a cultura europeia representa a civilização. Essa concepção justifica a colonização das Américas e da África como um processo civilizador e uma benfeitoria. Mesmo após o término da colonização, o sistema de pensamento europeu prevalece como discurso de elites hegemônicas que incorporam os valores culturais da metrópole e silenciam, desvalorizam e ocultam as tradiçôes, costumes, práticas e rituais de grupos sociais subalternizados. Esse processo pode ser observado, por exemplo, na sociedade brasileira, após o fim do período colonial.

Apesar de introduzir a temática de gênero e raça no pensamento póscolonial, ao tratar da sexualidade em dois capítulos do seu livro, relacionados à "mulher de cor e o branco" e "o homem de cor e a branca", a concepção de sujeito em Fanon (2008) permanece atrelada ao homem negro colonizado.

7 A época da conquista dos povos denominados indígenas pelos europeus é conceituada, na historiografia ocidental, como a descoberta da América, situada no ano de 1492 (TODOROV, 2010). Edmundo O'Gorman (1976) critica a ideia de descobrimento, sustentando a "invenção da América", relacionada com as viagens realizadas por Colombo. no final do século XV e início do século XVI. Enrique Dussel (2012) destaca a importância da tese de O'Gorman. A conquista, fundamentada na ideia de descobrimento do "Novo Mundo", caracteriza a construção do mito da modernidade. Desde o fim do século XV, a Europa passa a se afirmar como o centro do mundo. 
Nesse sentido, a questão da subjetividade feminina não é explorada por Fanon (BALLESTRIN, 2017).

A colonialidade, de acordo com Quijano (2014), se prolonga para além do colonialismo, impondo-se às intersubjetividades. Mesmo com o término do período colonial, prevalecem formas de colonização epistêmica na América Latina, Caribe e África. No processo de colonização, a invenção do conceito de "raça" possibilitou ao colonizador europeu classificar grupos étnicos culturalmente diferenciados como inferiores e selvagens. Desenvolvese, então, o "etnocentrismo colonial" e uma forma de estratificação que serve para classificar as comunidades indígenas existentes nas Américas e os povos africanos escravizados. Assim, "o etnocentrismo colonial e a classificação racial universal" nos auxiliam a compreender "[...] por que os europeus foram levados a sentir-se não só superiores a todos os demais povos do mundo, mas, além disso, naturalmente superiores." (QUIJANO, 2005, p. 121).

No entanto, um aspecto associado com o paradigma epistemológico da filosofia ocidental passou despercebido pelo pensamento pós-colonial. Pode-se observar que, na cultura e na filosofia ocidental, os discursos produzidos por homens tornaram-se hegemônicos, formulando normas, regras de conduta e mecanismos de controle da sexualidade das mulheres. A dominação masculina se estrutura no sistema simbólico, nos valores culturais, e constitui modos de sujeição e subjetividades. Todavia, há resistências às relaçôes de poder e às formas de submissão e sujeição.

Para abordar o sistema colonial moderno, María Lugones (2014) desenvolveu o conceito de "colonialidade de gênero", referindo-se aos processos de colonização e dominação impostos pelos colonizadores europeus aos povos da América. A reflexão acerca do sistema capitalista moderno, em Lugones (2007, 2008, 2011, 2014), se baseia em uma retomada dos processos de colonização no continente americano. $\mathrm{Na}$ visão da filósofa argentina, há uma intersecção entre raça, gênero e sexualidade.

\section{GêNero e Poder em María Lugones}

A colonização dos povos denominados indígenas pelos europeus teve como consequência a imposição de modelos de pensamento e modos de ser. Nesse contexto, o saber nas sociedades colonizadas constitui uma forma de conhecimento subalterno que supervaloriza a cultura ocidental e desvaloriza 
as culturas dos povos originários. A imposição da cultura ocidental resultou em processos de aculturação e perda da identidade, na América. No sistema moderno/colonial, os modos de assimilação constituem práticas de destruição dos “[...] mundos de outras pessoas." (LUGONES, 1987, p. 16).

No processo de colonização, além das formas de classificação baseadas na noção de raça, mencionadas por Aníbal Quijano (2005), teriam sido engendradas categorizações de gênero. María Lugones (2007) acrescenta o sistema de gênero colonial na análise da colonialidade do poder. Esse sistema está centrado em uma estrutura binária e hierárquica, na qual o patriarcado institui práticas de opressão e a heterossexualidade se caracteriza como modelo de organização da vida. Por sua vez, a epistemologia feminista branca desconsiderou a intersecção entre "raça”" e gênero, em suas teorias.

Segundo María Lugones (2014, p. 935), “[...] a lógica categorial dicotômica e hierárquica é central para o pensamento capitalista e colonial moderno sobre raça, gênero e sexualidade." O termo "mulheres de cor" corresponde a uma identidade orgânica que une indígenas, mestiças, mulatas, negras, porto-riquenhas, chicanas, mexicanas e outras vítimas de múltiplas formas de dominação e opressão. O "sistema moderno colonial de gênero" é associado às formas de colonialidade do saber, do poder e do ser, no contexto pós-colonial. Há uma intersecção entre as categorias de raça, gênero, classe e sexualidade (LUGONES, 2007).

O modo de organização moderno/colonial de gênero se funda no dimorfismo biológico, em uma concepção de heterossexualidade normativa e no patriarcado. Com a invenção do conceito de "raça", analisado por Quijano (2005), estabelecem-se formas hierárquicas de classificação de pessoas e grupos étnicos. Esse modo de classificação por hierarquia se perpetua na sociedade capitalista global. Por meio do sistema de classificação capitalista, a colonialidade do poder exerce um controle das relaçóes de produçáo e da sexualidade. Assim, concebem-se identidades culturais associadas a um determinado espaço geográfico, consolidando-se com a construção de identidades geopolíticas das populaçôes. América, Europa, Índia, África e Ásia referem-se a identidades "raciais".

Diferentemente do feminismo ocidental, a filósofa argentina propóe compreender o patriarcado a partir do que chama de "colonialidade do gênero" (LUGONES, 2008, p. 73). Para tratar da colonialidade, María Lugones (2008) toma como referência Aníbal Quijano (2005, 2014). No 
entanto, a filósofa considera a teoria de Quijano incompleta, por não abordar aspectos específicos da questão de gênero, na análise do sistema colonial/ moderno. Dessa maneira, é acrescentada a ideia de "colonialidade de gênero", para discorrer acerca das relaçóes coloniais e pós-coloniais na América Latina.

No tocante às relaçóes coloniais, reproduziram-se dicotomias e concepçóes simbólicas fundamentadas em hierarquias que diferenciaram humanos e não humanos. Essa categorização é essencial para a compreensão da "dicotomia central da modernidade colonial":

Começando com a colonização das Américas e do Caribe, uma distinção dicotômica, hierárquica entre humano e não humano foi imposta sobre os/ as colonizados/as a serviço do homem ocidental. Ela veio acompanhada por outras distinçóes hierárquicas dicotômicas, incluindo aquela entre homens e mulheres. Essa distinção tornou-se a marca do humano e a marca da civilização. Só os civilizados são homens ou mulheres. Os povos indígenas das Américas e os/as africanos/as escravizados/as eram classificados/as como espécies náo humanas - como animais, incontrolavelmente sexuais e selvagens. (LUGONES, 2014, p. 936).

Nessa perspectiva, o entendimento das hierarquias construídas pelo discurso da filosofia ocidental, bem como do pensamento colonial que caracteriza a modernidade, nas sociedades latino-americanas, é essencial para uma reflexão crítica sobre as formas de discriminação e os mecanismos de estigmatização que constituem a centralidade discursiva masculina, na cultura do Ocidente. Para tanto, como sugere María Lugones (2014), é necessário estabelecer uma intersecção entre as categorias conceituais de raça, classe, gênero e sexualidade.

O "sistema moderno-colonial de gênero" funciona como instrumento de poder que impóe às mulheres relaçóes de subalternização. Na modernidade, a concepção de poder caracteriza-se como eurocêntrica à medida que supervaloriza a cultura e o modo de produção de conhecimento Ocidental, desvalorizando outras formas de saber e modos de ser. No "sistema modernocolonial de gênero", são apontadas formas de dominação nas esferas do sexo, do trabalho, da autoridade coletiva e da subjetividade (LUGONES, 2008).

Produtos e recursos ligados à sexualidade têm como referência a cultura patriarcal e os padróes de comportamento direcionados pela heterossexualidade como norma. A concepção de "raça", construída pelos discursos do Ocidente, instaura hierarquias e dicotomias. Assim, pressupóe-se a existência de raças 
superiores e raças inferiores. No entanto, a colonialidade não se reduz a um processo de dominação e poder que estabelece classificaçóes hierárquicas. Dessa maneira, são formuladas hierarquias entre as identidades europeias, indígenas, africanas e asiáticas e, nesse contexto, os grupos hegemônicos europeus ocupam um espaço privilegiado, sendo tidos como superiores. $\mathrm{O}$ eurocentrismo hegemônico marginaliza e exclui indivíduos e grupos em seu espaço geográfico e se mantém nas estruturas ontológicas das sociedades colonizadas, formando as subjetividades e intersubjetividades. "O nascimento da colonialidade e sua extensão, profunda e prolongada ao redor do planeta, estão estreitamente relacionadas com o colonialismo." (LUGONES, 2008, p. 79).

Sustentada na teoria de Aníbal Quijano, María Lugones (2008) evidencia que o modo de produçáo de conhecimento intitulado racional remete ao contexto do século XVII e às localidades hegemônicas da Holanda e da Inglaterra. Com a expansão do capitalismo, no mundo, esse modo de produção do conhecimento e a própria cultura eurocêntrica se tornaram globais, difundindo-se em várias regiôes do mundo. "Esta forma de conhecimento foi imposta na totalidade do mundo capitalista como a única racionalidade válida e como emblema da modernidade." (LUGONES, 2008, p. 81).

Para uma imposição global, é construído um mito, no qual se considera a Europa como a sociedade mais avançada do planeta e o próprio símbolo de civilização e humanidade. Desde esse ponto, constrói-se uma diferenciação entre povos superiores e povos inferiores, grupos dotados de racionalidade e grupos irracionais, povos primitivos e sociedades civilizadas, conjunturas modernas e contextos tradicionais. A Europa estaria situada no momento mais avançado da humanidade. Nesse sentido, a ideia de civilizaçâo fundamenta a condição de ser humano e justifica a dominação como uma benfeitoria, um processo civilizador. São considerados humanos somente os grupos tidos como superiores e civilizados, ou conceituados como modernos.

A distinção entre civilizados e primitivos relaciona-se com a classificação hierárquica entre humanos e não humanos, imposta pelo sistema colonial (LUGONES, 2011; BIDASECA, 2014). Sociedades indígenas e povos africanos são definidos como não humanos, primitivos e selvagens, de acordo com a classificação hierárquica do sistema colonial/moderno. Os discursos que definem as formas de categorização do sistema colonial/moderno "racial" concebem as pessoas que vivem nesses espaços geográficos como privadas de racionalidade. Essa classificação hierárquica acrescenta que o padrão de 
comportamento heterossexual e o "paradigma sexual binário" (LUGONES, 2008, p. 84) estão associados à concepção de humanidade.

As formas de discriminação, estigmatização e exclusão de pessoas intersexuais, por exemplo, são efeitos de modos de subjetivação provenientes da colonialidade de gênero. Para adequação aos padrôes de normalidade estabelecidos, o saber médico do Ocidente converte, por meios cirúrgicos e hormonais, os indivíduos intersexuais em homens e mulheres. O sistema de gênero moderno se baseia, portanto, na noção biológica de dimorfismo sexual (LUGONES, 2008). Na classificaçáo hierárquica dos grupos étnico-culturais, homens e mulheres brancas são civilizados/as, enquanto os outros grupos são considerados não humanos.

O homem europeu, burguês, colonial moderno tornou-se um sujeito/ agente, apto a decidir, para a vida pública e o governo, um ser de civilização, heterossexual, cristáo, um ser de mente e razão. A mulher europeia burguesa não era entendida como seu complemento, mas como alguém que reproduzia raça e capital por meio de sua pureza sexual, sua passividade, e por estar atada ao lar a serviço do homem branco europeu burguês. (LUGONES, 2014, p. 936).

María Lugones (2014) cita a seguinte frase de Protágoras: "O homem é a medida de todas as coisas." Essa frase emblemática é uma referência que se encontra na base da filosofia ocidental, segundo a qual o homem representa o modelo de perfeição. Com as teorias raciais, essa concepção se estende, delimitando o universo da humanidade somente para os homens brancos. Para se tornarem humanos, homens e mulheres indígenas, africanos/as e afrodescendentes precisam se assemelhar ao homem branco europeu.

Como consequência da colonização, saberes e práticas comunitárias que primavam pela integração entre ser humano e cosmos passam a ser tomadas como primitivas. É necessário evidenciar a inferioridade dessas concepçôes, para justificar a exploração econômica da natureza.

A devastação do meio ambiente é vista como necessária a fim de se promover uma ordem racional, baseada em uma administração "científica" da natureza, voltada para a correção do meio ambiente (SHIVA, 2003). Dessa maneira, o poder capitalista justifica a degradação e a destruição da natureza ${ }^{8}$ como necessárias para o desenvolvimento e o progresso da humanidade.

8 Vandana Shiva (2003) demonstra que o paradigma da monocultura reduz as florestas a fontes fornecedoras de matéria-prima para o mercado capitalista. A problemática a propósito da destruição 
Teorias da Antropologia e da Arqueologia corroboram a perspectiva de María Lugones. Estudos mostram a existência de sociedades indígenas nas quais as mulheres assumem posiçóes de poder, como é o caso de "mulheres guerreiras que chefiavam suas tribos", denominadas "amazonas" pelos colonizadores europeus (FUNARI; PIÑON, 2016, p. 47). Representações na cerâmica marajoara, no Brasil, por exemplo, revelam a posição de destaque das mulheres nas tribos indígenas da ilha de Marajó.

Ademais, pesquisas na arqueologia evidenciam que, em outras sociedades indígenas da América do Sul, as mulheres ocupavam lugar de destaque na hierarquia da estrutura social. Em sociedades indígenas "[...] que viviam no Brasil, na Venezuela e nas ilhas caribenhas", havia divindades “[...] femininas e a linhagem era materna, tanto no que se refere à descendência como à herança $[. .$.$] ", além disso, observa-se "[...] a existência de sociedades$ indígenas que reconhecem mais do que dois sexos." (FUNARI; PIÑON, 2016, p. 48-49). María Lugones (2008, p. 86) reforça essas constatações, ao ressaltar "[...] que muitas comunidades tribais de Nativos Americanos eram matriarcais", reconhecendo "positivamente tanto a homossexualidade como o 'terceiro' gênero $[. .$.$] "$

Nas sociedades ocidentais, até praticamente o século XX, mulheres não ocupavam espaços de poder, assim como não participavam das discussôes na esfera pública. Para as mulheres, a colonização resulta em um "[...] processo dual de inferiorização racial e subordinação de gênero." (LUGONES, 2008, p. 88). Há, então, uma concepção de inferioridade imposta às mulheres e aos grupos étnicos indígenas e africanos, justificando-se a colonização como uma missão civilizatória.

Para destacar as especificidades da cultura patriarcal no Ocidente, María Lugones (2008) se refere à teoria de Oyéronké Oyěwùmí (1997). Ao analisar a língua e a cultura ioruba, Oyěwùmí (1997) defende a tese de que “[...] o gênero não era um princípio organizador na sociedade Ioruba antes da colonização Ocidental" (apud LUGONES, 2008, p. 87). Em vista disso, nas sociedades iorubas e em determinadas comunidades indígenas da América, não haveria uma oposição binária entre os gêneros, antes da chegada dos colonizadores europeus. Com o colonialismo imposto às sociedades africanas, ocorreram mudanças nas relaçóes de gênero, por intermédio da incorporação

da natureza é tratada por Maria Mies (1998), que critica o modelo de produção do patriarcado capitalista. Questôes referentes à contaminação das águas e do ar com produtos tóxicos, a monocultura e a degradação das áreas litorâneas são abordadas por Roy May (2004), no livro Ética e meio ambiente. 
das hierarquias e da dicotomia binária dos sexos. Com a colonização, na sociedade ioruba, os homens teriam incorporado os padróes morais da cultura patriarcal do Ocidente.

\section{A TEORIA DE GÊNERo EM OYÈronKÉ OYěWÙMí}

Além da oposição binária e das diferenciações classistas e étnicoraciais, a filosofia ocidental estabeleceu uma distinção entre corpo e mente. Acrescentam-se ao binarismo epistêmico do discurso eurocêntrico do Ocidente concepçóes dicotômicas e hierárquicas. No discurso hegemônico da cultura ocidental, adquiriram relevância as teorias biológicas acerca da natureza humana (OYĚWÙMÍ, 2017; NASCIMENTO, 2019).

No pensamento filosófico ocidental, o homem é concebido como um ser dotado de razão, enquanto a mulher tem um corpo e afetos. A razão possibilita ao homem a participação nas atividades decisórias da sociedade como um todo. Nas teorias políticas do Ocidente, a noção de cidadania está associada ao masculino. Como sugere Oyĕwùmí (2017, p. 47), as “[...] dualidades como natureza/cultura, público/privado e visível/invisível, são variaçôes do tema da ordem hierárquico corporal masculino/feminino, localizadas diferencialmente em relação ao poder [...]"

A teoria da construção social das categorias de gênero foi desenvolvida pela segunda fase da epistemologia feminista. Com ela, emerge a oposição entre a teoria da construção social do gênero e o determinismo biológico. No entanto, "[...] as categorias sociais derivaram sua legitimidade e poder da biologia", sendo que "o social e o biológico se retroalimentam." (OYĚWÙMÍ, 2017, p. 49). A biologia consiste em uma construção social constantemente ressignificada, à medida que se realimenta com a produção de conhecimento baseada no paradigma epistêmico eurocêntrico. A concepção de gênero do Ocidente fundamenta-se no dimorfismo sexual formulado pela teoria biológica.

Para Oyěwùmí (2017), é falsa a diferenciação entre sexo e gênero. Por outro lado, na racionalidade androcêntrica do Ocidente, "[...] o gênero náo pode existir sem o sexo já que o corpo se assenta diretamente como a base de ambas as categorias." (OYĚWÙMÍ, 2017, p. 50). Contudo, a razão androcêntrica não é atemporal e muito menos universal. $\mathrm{O}$ mesmo se afirma a propósito da submissão das mulheres. Teorias produzidas no Ocidente 
transformaram em um discurso de verdade a ideia segundo a qual as mulheres sempre foram submissas ao patriarcado, em todas as culturas e em todo e qualquer contexto geográfico e histórico. Logo, a ideia de submissão das mulheres torna-se uma verdade universal e atemporal, produzida pelo discurso eurocêntrico. A partir de "uma perspectiva multicultural", o feminismo "[...] exibe as mesmas características etnocêntricas e imperialistas dos discursos ocidentais que busca subverter." (OYĔWÙMÍ, 2017, p. 55).

Em uma perspectiva multicultural, as noçôes de macho e fêmea são construçóes sociais que variam de acordo com a cultura, o espaço social e o contexto histórico. Assim, "[...] as relações de gênero são relaçóes sociais e, portanto, estabelecidas historicamente e delimitadas culturalmente." (OYĔWÙMÍ, 2017, p. 51). Antes do processo de colonização, nas sociedades iorubás, a biologia não determinava a posição social do indivíduo. Por meio de uma análise da linguagem, Oyěwùmí (2017) constata que, na cultura iorubá, inexistem categorizaçóes que hierarquizam o masculino e o feminino, nas relaçôes sociais. Em vista disso, os papéis sociais desempenhados por quem governa, ou quem exerce a função de sacerdote ou sacerdotisa, dependem de fatores relacionais e dinâmicos associados à senioridade. Em seu sistema de conhecimento, a cultura iorubá possui elementos orais e visuais. $\mathrm{O}$ mundo é compreendido como vínculo e interligação entre partes que formam um todo.

Diferentemente da cultura ocidental, as formas de hierarquização estão associadas à ideia de senioridade. Ademais, "[...] em muitas sociedades da África Ocidental não há especificidade de gênero.” (OYĚWÙMÍ, 2017, p. 61). As experiências e modelos de governo, organização social e cultura do Ocidente servem de referência para analisar as sociedades africanas. Com o referencial baseado no paradigma do discurso hegemônico eurocêntrico, as sociedades africanas não possuem Estado, filosofia e nem história. A filósofa africana Nkiru Nzegwu questiona a concepção das sociedades Igbó e Iorubá como patriarcais (apud OYĔWÙMÍ, 2017).

Oyěwùmí $(2017$, p. 75$)$ sugere que as análises sobre as sociedades africanas tomam como referência o modelo epistemológico ocidental. Assim, o conhecimento produzido na África necessita da legitimação do Ocidente, para se afirmar como autêntico. Dessa forma, "[...] a falta de reconhecimento que a linguagem leva consigo o sentido do mundo de um povo implica aceitar que as categorias ocidentais são universais.” (OYĚWƯMÍ, 2017, p. 78). Isto ocorre com a epistemologia feminista do Ocidente, tendo em vista que “[...] a pressuposição e a utilização universal das categorias de patriarcado e 
'mulher' resulta em um posicionamento etnocêntrico e manifesta a hegemonia do Ocidente sobre outras classificações culturais.” (OYĚWÙMÍ, 2017, p. 59). Categorias conceituais utilizadas para analisar as sociedades africanas se amparam em uma perspectiva biológica acerca do condicionamento de papéis sociais.

De acordo com a teoria de Oyěwùmí (2017), na língua iorubá, inexistem categorizaçóes de gênero para especificar homens, mulheres, filhos, filhas, irmãos e irmãs. Por outro viés, a colonização europeia na sociedade iorubá teve como efeito a transposição patriarcal na cultura e na história no contexto pós-colonial.

Oyěwùmí (2017) analisa o modo de organização da sociedade Òyọ, uma sociedade iorubá em um momento anterior ao período colonial. $\mathrm{Na}$ perspectiva de Oyĕwùmí (2017), termos como oko e o $b a$ não possuem gênero. No contexto histórico que antecede a colonização, inexistiam as categorizaçôes de gênero, na sociedade iorubá. Na língua iorubá, o termo Ėnìyàn designa a humanidade. Esse termo não possui um gênero específico. Da mesma maneira, omọdé designa tanto meninas quanto meninos.

Termos da língua iorubá como obinrin e okùnrin, traduzidos comumente como macho e fêmea, não correspondem a uma sexualidade dimórfica associada ao gênero. Segundo Oyěwùmí (2017, p. 88), essas palavras não "[...] expressam masculinidade ou feminilidade, pois essas categorias não existiram na vida ou no pensamento Iorubá." Na língua iorubá, obinrin e okùnrin designam diferenciaçôes dos corpos, destacando o papel de cada um na procriação. A organização do mundo iorubá fundamenta-se em relaçóes sociais, na linhagem e na senioridade. Na concepção iorubá, obintin tem a função procriadora, mantendo a sua condição de Ėnìyàn.

$\mathrm{Na}$ linguagem, encontram-se os valores culturais de uma determinada sociedade. $\mathrm{O}$ modo de categorização social pela idade relativa constitui o princípio de organização da sociedade iorubá. Nomes e prenomes não possuem gênero, na língua iorubá. No dialeto iorubá, emprega-se omodé para fazer referência ao rebento, ou à criatura, independentemente da diferenciação de gênero dos bebês. Omo refere-se tanto a meninas quanto meninos.

Por sua vez, a senioridade possui um caráter relacional e situacional. É o caso, por exemplo, da responsabilização de crianças mais velhas por uma atitude de desrespeito. Pressupóe-se que a criança mais velha teria mais consciência, por isso, atribui-se a ela mais responsabilidade. Nesse sentido, 
na língua iorubá, estão ausentes categorizaçôes conceituais de diferenciação hierárquica de gênero. Há especificação a propósito das diferenças anatômicas entre homens e mulheres relacionadas com a procriação. No entanto, essas diferenças não apresentam significado ou projeção no modo de organização social, o qual tem como referência a senioridade concebida de forma relacional e situacional.

Outro aspecto que diferencia as formas de hierarquização está associado a lideranças femininas, nas cidades iorubás. Efúnșetán Aníwúrà, por exemplo, foi uma İlálóde, uma liderança política da cidade de İbàdàn, por meio da linhagem de sua mãe. Ao abordar as lideranças políticas de Òyó, historiadores e historiadoras desconsideram o fato de, na língua iorubá, não haver referência ao gênero, no tocante a termos como oba e alááfin. Traduzir oba como rei não condiz com o significado expresso pela língua e a cultura iorubá. Na língua iorubá, aláąin e oba podem abranger tanto o masculino quanto o feminino (OYĚWÙMÍ, 2017). Oyěwùmí (2017) menciona os cargos políticos ocupados pela İyálóde, na organização social iorubá. A İyálóde tem um lugar de destaque como liderança política na antiga Òyọ́. O termo İyálóde remete à senioridade, designando a "[...] fêmea madura para o cargo de assuntos públicos.” (OYĚWÙMÍ, 2017, p. 191).

Diferentemente das sociedades ocidentais, nas quais as mulheres permaneceram no espaço privado do lar, teorias mostram que, em sociedades africanas, como a iorubá, as mulheres comercializavam nos mercados, exerciam cargos públicos de liderança política, além de serem sacerdotisas (OYĔWÙMÍ, 2017). Em vista disso, os papéis sociais, na sociedade iorubá que antecede a colonização europeia, estão relacionados com a linhagem e não com o gênero. É o caso de pessoas que exercem a função de sacerdotisaadivinha ou sacerdote-adivinho. Podem ser tanto homens quanto mulheres. Para isso, basta que tenham contato com o Ifá, a divindade da adivinhação, e se tornem sacerdotes ou sacerdotisas, por meio do aprendizado.

O tipo de organização da sociedade iorubá anterior à colonização suscita um questionamento acerca da concepção universal e atemporal da hierarquização social baseada em gênero e a divisão do trabalho. $\mathrm{Na}$ velha Òyó, as relaçôes sociais apoiam-se na linhagem e na senioridade, não sendo determinadas pela diferenciação de gênero. Assim, o gênero consiste em uma construção teórica produzida por discursos das ciências do Ocidente. Na perspectiva de Oyěwùmí (2017, p. 147), “[...] nos discursos ocidentais, o gênero se concebe primeira e principalmente como uma categoria biológica 
dicotômica, utilizada como a base da construção das hierarquias sociais.” As hierarquias são estabelecidas a partir de diferenças corporais. $\mathrm{O}$ ser masculino detém privilégios no modo de organização social das sociedades ocidentais, em decorrência de sua estrutura anatômica.

$\mathrm{Na}$ língua inglesa, a palavra man abrange a humanidade como um todo, tendo em vista que faz referência tanto a homens como a mulheres. O termo homem designa a espécie humana em geral. A virilidade se associa à masculinidade, ao poder patriarcal e à participação dos homens no espaço público. O biológico e o social estão associados nos discursos das ciências ocidentais, constituindo uma relação fundada na hierarquia entre homens e mulheres.

Todavia, a teoria de gênero de Oyěwùmí enfatiza que o patriarcado não apresenta uma universalidade. Oyěwùmí (2017) evidencia que ser do sexo masculino não é um pré-requisito para assumir cargos políticos em governos, nas sociedades iorubás. Há povos iorubás governados por mulheres, tanto no século XX quanto em contextos históricos anteriores ao período colonial. Por outro viés, no Ocidente, o gênero aparece "[...] como uma categoria fundamental e universal”, entretanto, essa diferenciação e hierarquização não correspondem ao "marco de referência" da sociedade iorubá (OYĚWÙMÍ, 2017, p. 187).

Várias críticas foram direcionadas para a teoria de gênero desenvolvida por Oyěwùmí. Essas críticas também são dirigidas para María Lugones. $\mathrm{Na}$ visão de Rita Segato (2012, p. 116), María Lugones e Oyěwùmí “[...] afirmam a inexistência do gênero no mundo pré-colonial.” A antropóloga argentina mostra que esse posicionamento desconsidera "[...] evidências históricas e relatos etnográficos que confirmam, de forma incontestável, a existência de nomenclaturas de gênero nas sociedades tribais e afro-americanas." (SEGATO, 2012, p. 116). Nesse sentido, haveria nessas sociedades uma forma incipiente de patriarcado. Outra crítica à teoria de gênero desenvolvida por Oyěwùmí é feita por Bibi Bakare Yusuf (2004), que questiona a possibilidade de alcançar um significado original anterior à colonizaçáo, como uma essência de significados dos signos da língua iorubá.

Outra crítica é apontada por Luciana Ballestrin (2017), que questiona a falta de metodologia na apropriação que Lugones faz da teoria de Oyěwùmí. Dessa maneira, os estudos específicos da cultura iorubá são tomados como referência para sustentar a ausência de gênero nas sociedades pré-coloniais, 
"[...] sem a devida referência metodológica", sendo generalizados por Lugones para todo o mundo pré-colonial (BALLESTRIN, 2017, p. 1048). As críticas apontam inconsistências nas teorias de Oyěwùmí e Lugones. No entanto, as noçôes de poder, multiplicidade ontológica e multiculturalismo, em Lugones, nos permitem compreender e situar o posicionamento da filósofa na corrente teórica do pensamento pós-colonial. ${ }^{9}$

\section{Poder, multiplicidade ontológica e multiculturalismo}

A teoria de María Lugones (2003) sugere um deslocamento epistêmico no tocante à problemática das relaçóes de poder. Esse deslocamento tem como referência um multiculturalismo radical, que defende a "[...] mudança de uma lógica de opressão para uma lógica de resistência.” (LUGONES, 2014b, p. 68). A lógica da opressão exerce seu poder de dominação revestida por um "multiculturalismo ornamental", o qual serve como máscara para reproduzir discursos baseados na hegemonia cultural do Ocidente, no eurocentrismo epistêmico e em uma concepção ilusória de universalidade. $\mathrm{O}$ feminismo burguês branco desconsiderou a intersecção e a inseparabilidade entre raça, classe, sexualidade e gênero, reproduzindo relaçóes de dominação e submissão com as mulheres não brancas.

Assim, Lugones (2014b) faz uma crítica ao uso da noção de interseccionalidade. Não basta reconhecer as categorias de subordinação e sujeição, na análise da intersecção entre raça, classe, sexualidade e gênero. Nesse sentido, a intersecção pode esconder o caráter inseparável das formas de opressão. Logo, María Lugones (2014b, p. 79) propôe a radicalização

\footnotetext{
9 Na visão de Ochy Pichardo (2014, p. 47), a teoria pós-colonial caracteriza-se como uma proposta pós-estruturalista e pós-funcionalista que busca "[...] reinterpretar a colonizaçáo como parte de um processo global transnacional e transcultural [...]" Por outro viés, o feminismo decolonial se coloca como uma crítica do sistema de gênero/moderno/colonial, problematizando as bases teórico-epistemológicas do feminismo. Para Yuderkys Espinosa-Miñoso (2014, p. 7), o feminismo descolonial assume uma postura não eurocêntrica, constituindo um "[...] pensamento produzido por vozes marginais e subalternas das mulheres e do feminismo." Como ressalta Jules Falquet (2014), o Grupo LatinoAmericano de Estudos, Formação e Ação Feminista (GLEFAS) defende um pensamento feminista descolonizador e emancipatório. Luciana Ballestrin (2020, p. 3) considera o "feminismo de(s)colonial" como um "feminismo pós-colonial e terceiro mundista", o qual propóe a descolonizaçáo do gênero, do conhecimento, do feminismo e do Estado, concebido "como um feminismo subalterno" que articula as perspectivas latino-americanas, indígenas, comunitárias, lésbicas e afrodescendentes. Ao sugerir um giro decolonial e um projeto descolonizador, o feminismo decolonial radicaliza o pensamento póscolonial, defendendo a inclusão do debate sobre a problemática de gênero nas questôes que envolvem o sistema moderno/colonial.
} 
do multiculturalismo, enfatizando as múltiplas formas de resistência à “epistemologia eurocêntrica”.

Além disso, uma visão binária do poder reduz a complexidade de modos de interação marcados por redes relacionais múltiplas, difusas e complexas. As relaçôes de poder são vistas a partir da noção de multiplicidade ontológica (LUGONES, 2003; MOYA, 2006). O exercício do poder consiste em redes relacionais dinâmicas por meio de práticas complexas de opressão (oprimir/ser oprimido) acompanhadas por formas de resistência.

Em um movimento contínuo, a noção de "subjetividade ativa" pode propiciar a resistência e a emancipação. Nesse sentido, a coalizão de coletividades, como é o caso dos movimentos sociais, pode ser direcionada para a emancipação de indivíduos, grupos e sociedades (LUGONES, 2003). Além da razão androcêntrica, o racismo epistêmico hierarquiza os saberes, tendo como reflexo a invisibilidade do conhecimento produzido fora do eixo epistemológico Europa/Estados Unidos.

Com a concepção de multiplicidade ontológica, María Lugones (2003) sustenta o caráter heterogêneo do meio social. Em um mesmo espaço geográfico e social, podem coexistir mundos múltiplos. O livro Pilgrimages/ Peregrinajes evidencia a dinâmica das relaçôes sociais no movimento de opressão e resistência. A noção de "subjetividade ativa" constitui um modo de resistência à lógica da dominação. María Lugones (2014b, p. 73) defende “[...] a inseparabilidade lógica de raça, classe, sexualidade e gênero.” Por isso, para compreender a lógica da opressão, é necessário levar em conta a interconexão entre as categorizaçóes interseccionais de raça, classe, sexualidade e gênero.

A partir da ideia de intersecção, é possível ter uma visão mais abrangente das relações de poder, tendo em vista que essas não se reduzem a interaçóes e práticas de opressão entre homens e mulheres. Na multiplicidade ontológica de sistemas de opressão, as múltiplas redes relacionais de poder caracterizamse pela complexidade, sendo necessário incluir e "[...] reconhecer a relação de poder entre a mulher branca e a mulher de cor." (LUGONES, 2014b, p. 74). Múltiplas formas de opressão estão interseccionadas, nas sociedades. As relaçôes de poder pressupóem a existência de lógicas de resistência. Os modos de opressão interseccionados funcionam como mecanismos de controle e desmobilização. Com a prevalência do discurso hegemônico eurocêntrico, instituem-se relaçóes de opressão e poder baseadas na lógica binária, na 
heterossexualidade e na hierarquização fundada na dicotomia de gênero, "raça" e sexualidade.

O multiculturalismo radical se aproxima dos feminismos das Mulheres de Cor. Lugones (2014a, 2014b) cita a teoria de Glória Anzaldúa como uma referência da perspectiva feminista de fronteira. Anzaldúa (2009) alude à linguagem de fronteira como prática de resistência, citando como exemplo o espanhol chicano. "O espanhol chicano é considerado deficiente pelos puristas e, pela maioria dos latinos, uma mutilação do espanhol.” (ANZALDUÁ, 2009, p. 306). O/a imigrante latino-americano/a na América do Norte funde espanhol e inglês, criando uma nova linguagem, afirmando uma identidade mestiça de fronteira.

Línguas podem representar modos de resistência à dominação, como é o caso do pachuco. "Pachuco (a língua dos zoot suiters) é uma língua de rebelião, ao mesmo tempo contra o espanhol padrão e contra o inglês padrão. É uma língua secreta. Adultos da cultura e estranhos náo podem entendê-la." (ANZALDUÁ, 2009, p. 309). No modo de falar chicano, sílabas iniciais são omitidas. Assim, o sujeito mestiço resiste à dominação cultural, transformando a língua da metrópole colonizadora. Entende-se a afirmação da língua chicana como uma forma de superar o silêncio e afirmar a identidade indígena e espanhola. O/a chicano/a possui uma identidade de fronteira rodeado por dois idiomas, o espanhol e o inglês. Dessa maneira, a comunidade chicana se identifica com a cultura indígena, funcionando como prática de resistência e uma identidade cultural de fronteira.

A proposta de Lugones (2014) é destacar as resistências à opressão, tendo em vista a historicidade das relaçóes de poder. $\mathrm{O}$ feminismo descolonial ${ }^{10}$ situa-se no pensamento de fronteira, enfatizando as histórias de resistência à colonialidade, exemplificada por modos de ser relacionados com o comunalismo e formas de afirmação da existência. Em sua trajetória emancipatória, o feminismo descolonial precisa expandir-se cada vez mais, na "[...] lógica da diferença, da multiplicidade e da coalizão no ponto da diferença." (LUGONES, 2014, p. 949).

No discurso eurocêntrico, há uma linha histórica que sustenta a existência ontológica de um Ocidente puro e democrático, associada a espaços

\footnotetext{
${ }^{10} \mathrm{Na}$ perspectiva de Julieta Paredes (2014), descolonizar o gênero significa reconhecer que o patriarcado existe antes da colonização. Em sociedades pré-coloniais, como na Bolívia, já existiam formas de opressão das mulheres, fator que leva Paredes (2014) a defender que o patriarcado antecede a colonização.
} 
geográficos e contextos que incluem o Médio Oriente, a Mesopotâmia, a Grécia clássica, o Império Romano, as metrópoles hegemônicas da Europa e os Estados Unidos. Histórias, saberes, memórias de povos, culturas e modos de viver que se situam fora desse eixo hegemônico são apagados, inferiorizados e silenciados. "Monoculturalismo e monolingualismo expressam o eurocentrismo que acompanhou a história do colonialismo ocidental." (LUGONES, 2014b, p. 77).

No tocante às críticas suscitadas por Ballestrin (2017), segundo a qual estudos específicos de caso seriam referências para construir uma proposição universal que abrangeria todo o mundo colonial, é preciso ressaltar que o multiculturalismo radical de Lugones (2014b) rejeita a ideia de unidade e uma concepção essencialista a propósito das identidades. A crítica dirigese ao eurocentrismo epistemológico fundamentado em uma lógica binária estruturante e opressiva. Enfatizam-se as afiliações e coalizóes como práticas de resistência ao sistema de opressão. Há uma multiplicidade de conhecimentos, modos de vida, linguagens e culturas.

A dominação cultural se institucionaliza, por meio de políticas monoculturais e monolinguísticas, como a imposição do uso do inglês como língua hegemônica. Além da institucionalização de uma língua hegemônica, as políticas incluem a dimensão epistemológica com a imposição de uma maneira específica de produção do conhecimento. Culturas e modos de vida fora do eixo epistêmico constituído pelo discurso eurocêntrico hegemônico são silenciados, marginalizados e apagados. Esse processo de exclusão epistêmica pode ser observado com as múltiplas culturas dos povos indígenas da América, assim como das sociedades africanas.

\section{ConsideraÇóEs Finais}

A perspectiva de María Lugones evidencia que o paradigma epistêmico do Ocidente hegemônico se caracteriza pela oposição binária de gênero, a qual institui e institucionaliza hierarquias. O poder é ocupado por homens brancos heterossexuais, enquanto mulheres e outros grupos étnico-culturais são considerados não humanos e inferiores, nas relaçôes hierárquicas. As relaçóes de poder se caracterizam pela complexidade, sendo estabelecidas com a colonialidade entre mulheres brancas e mulheres de cor. 
Apesar do multiculturalismo e da multiplicidade ontológica próprias do mundo, a globalização do sistema econômico capitalista se reflete na difusão do paradigma epistemológico de produção do conhecimento e da cultura ocidental androcêntrica. A noção de "degeneração" é importante para imposição de uma superioridade biológica como justificativa para o domínio.

Há, por conseguinte, a ideia de inferioridade genética que legitima a hierarquia e as desvantagens sociais. A escolha pela teoria de gênero de Oyěwùmí permite reforçar o argumento de Lugones a respeito da multiplicidade ontológica e da hierarquização entre homens e mulheres, baseada na biologia, a qual estrutura e fundamenta o discurso eurocêntrico do sistema moderno/colonial. Assim, Lugones não propóe analisar a teoria de Oyěwùmí, para buscar inconsistências em sua tese, como é a intenção de Rita Segato. A teoria de gênero de Oyěwùmí enfatiza que o patriarcado não é universal e nem atemporal.

Outra noção importante na cultura ocidental consiste em uma concepção do corpo ligada ao gênero, à classe e às teorias raciais que concebem dicotomias e oposiçôes binárias entre masculino e feminino, bem como diferenciaçôes étnico-raciais e classistas entre etnias e classes sociais. Dessa maneira, pessoas com opções sexuais ou formas anatômicas que se distanciam do modelo heterossexual sofrem discriminaçóes.

Em sua concepção de multiculturalismo radical, Lugones rejeita a ideia de unidade e uma visão essencialista das identidades culturais. A crítica dirigese ao eurocentrismo epistemológico fundamentado na estruturação da lógica binária e dicotômica. Enfatizam-se as afiliaçóes e coalizóes como formas de resistência ao sistema de opressão. Há uma multiplicidade de conhecimentos, modos de vida, linguagens, culturas. Ao destacar a relevância da intersecção entre as categorizaçóes de gênero, "raça", classe e sexualidade na hierarquização estabelecida pelas dicotomias binárias e essencialistas do discurso eurocêntrico hegemônico, a teoria de Lugones contribui de forma significativa com a mudança de paradigma na abordagem do pensamento pós-colonial.

CARVAlHO, G. P. Postcolonial thought, gender, and power in María Lugones's theory: ontological multiplicity, and multiculturalism. Trans/Form/Açáo, Marília, v. 45, p. 311-338, 2022. Edição Especial. 
Abstract: The article reflects on María Lugones's concepts of gender, power, multiplicity, and multiculturalism, analyzing the way her theory is associated with postcolonial thought. In order to do so, it aproaches the perspective of postcolonial thought, and the notion of coloniality of power, considering the colonial/modern gender system. The postcolonial theories criticize the Western epistemological paradigm, and hierarchy based on the distinction between human and non-human, colonizer and colonized. When analyzing the colonial/modern system, María Lugones's perspective introduces the concept of gender in the analyses of the power relationships. Oyèronké Oyěwùmí's theory of gender is a reference to María Lugones. In the analysis of the coloniality of power, Lugones develops the idea of the intersection of race, class, gender, and sexuality, proposing decolonial feminism based on the identification of forms of resistance, and coalition in social movements for emancipation.

Keywords: Gender. Power. Coloniality. Multiculturalism.

\section{REFERÊNCIAS}

AMIN, Samir. El Eurocentrismo: crítica de una ideología. Traducción de Rosa Cusminsky de Cendrero. México: Siglo XXI, 1989.

ANZALDUÁ, Gloria. Como domar uma língua selvagem. Cadernos de Letras da UFF; Dossiê: Difusão da língua portuguesa, n. 39, p. 297-309, 2009.

BALLESTRIN, Luciana Maria de Aragão. América Latina e o giro decolonial. Revista Brasileira de Ciência Política, Brasília, n. 11, p.89-117, 2013.

BALLESTRIN, Luciana Maria de Aragão. Feminismos Subalternos. Estudos Feministas, Florianópolis, v. 25, n. 3, p. 1035-1054, 2017.

BALLESTRIN, Luciana Maria de Aragão. Feminismo De(s)colonial como Feminismo Subalterno Latino-Americano. Revista Estudos Feministas, Florianópolis, v. 28, n. 3, 2020.

BAKARE-YUSUF, Bibi. Yorubas don't do gender: a critical review of Oyeronke Oyěwùmís The Invention of Women: Making an African Sense of Western Gender Discourses. In: VVAA. African Gender Scholarship: Concepts, Methodologies and Paradigms. Dakar: Codesria, 2004. p. 61-81 (Codesria Gender Series).

BIDASECA, Karina. Los peregrinajes de los feminismos de color en el pensamiento de María Lugones. Estudos Feministas, Florianópolis, v. 22, n. 3, p. 953-964, 2014.

CANDAU, Vera Maria Ferrão. Diferenças culturais, Interculturalidade e Educação em Direitos Humanos. Educaçáo e Sociedade, Campinas, v. 33, p. 235-250, 2012.

CARVALHO, Guilherme Paiva; SILVA, Eliane Anselmo. Justiça social e multiculturalismo: as políticas de reconhecimento de identidades étnico-culturais no Brasil. Direitos Fundamentais e Justiça, ano 9, n. 31, p. 134-159, 2015.

CORONIL, Fernando. Naturaleza del poscolonialismo: del eurocentrismo al globocentrismo. In: LANDER, Edgardo (org.). La colonialidad del saber: eurocentrismo y ciencias sociales. Buenos Aires: CLACSO, Consejo Latinoamericano de Ciencias Sociales, 2000. 
CURIEL, Ochy. Construyendo metodologías feministas desde el feminismo decolonial. In: AZKUE, Irantzu Mendia et al. Otras Formas de (Re)Conocer: Reflexiones, herramientas y aplicaciones desde la investigación feminista. Donostia-San Sebastian: Hegoa, 2014.

DUSSEL, Enrique. Europa, modernidad y eurocentrismo. In: LANDER, Edgardo (org.). La colonialidad del saber: eurocentrismo y ciencias sociales. Buenos Aires: CLACSO, Consejo Latinoamericano de Ciencias Sociales, 2000.

DUSSEL, Enrique. 1492, El encubrimiento del otro. 1. ed. Buenos Aires: Docencia, 2012 (Obras Selectas, XIX).

ESPINOSA-MIÑOSO, Yuderkys. Una crítica descolonial a la epistemologia feminista crítica. El Cotidiano, México, n. 184, p. 7-12, 2014.

FANON, Frantz. Pele negra, máscaras brancas. Tradução de Renato da Silveira. Salvador: EDUFBA, 2008.

FALQUET, Jules. Las “Feministas autónomas” latinoamericanas y caribeñas: veinte años de disidencias. Universitas Humanística, Bogotá, v. 78, p. 39-63, 2014.

FUNARI, Pedro Paulo; PIÑON, Ana. A Temática Indígena na Escola. 1. ed. São Paulo: Contexto, 2016.

HALL, Stuart. Da diáspora: identidades e mediaçóes culturais. Belo Horizonte: Editora UFMG; Brasília: Representação da UNESCO no Brasil, 2003.

LUGONES, María. Playfulness, "World"-Travelling, and Loving Perception. Hypatia, v. 2, n. 2, 1987.

LUGONES, María. Pilgrimages/Peregrinajes: Theorizing Coalition against Multiple Opressions. Lanham, Md: Rowman \& Littlefield, 2003.

LUGONES, María. Heterosexualism and the Colonial/Modern Gender System.

Hypatia, v. 22, n. 1, p. 186-209, 2007.

LUGONES, María. Colonialidad y Género. Tabula Rasa, Bogotá, Colombia, n. 9, p.73101, 2008.

LUGONES, María. Hacia un feminismo descolonial. La manzana de la discordia, v. 6, n. 2, p. 105-119, 2011.

LUGONES, María. Rumo a um feminismo descolonial. Estudos Feministas, Florianópolis, v. 22, n. 3, p. 935-952, 2014 a.

LUGONES, María. Radical Multiculturalism and Women of Color Feminism. Journal for Cultural and Religions Theory, v. 13, p. 68-80, $2014 \mathrm{~b}$.

MALDONADO-TORRES, Nelson. On the Coloniality of Human Rights. Revista Crítica de Ciências Sociais, v. 114, p. 117-136, 2017. 
MIGNOLO; Walter. Cuáles son los temas de género y (des)colonialidad? Género y descolonialidad. 2. ed. Ciudad Autónoma de Buenos Aires: Del Signo, 2014.

MIGNOLO, Walter; JIMÉNEZ-LUCENA, Isabel; LUGONES, María;

TLOSTANOVA. Género y descolonialidad. 2. ed. Ciudad Autónoma de Buenos Aires: Del Signo, 2014.

MOYA, Paula M. L. Pilgramages/Peregrinajes: Theorizing Coalition against Multiple Opressions by María Lugones. Hypatia, v. 21, n. 3, p. 198-202, 2006.

NASCIMENTO, Wanderson Flor do. Oyèrónkẹ Oyěwùmí: potências filosóficas de uma reflexão. Problemata: Intertional Journal of Philosophy, v. 10, n. 2, p. 8-28, 2019.

NOGUERA, Renato. O Ensino de Filosofia e a Lei 10.639. 1. ed. Rio de Janeiro: Pallas: Biblioteca Nacional, 2014.

OYĔWÙMÍ, Oyèronké. La Invención de las Mujeres: Una perspectiva africana sobre los discursos occdentales del género. Traducción de Alejandro Montelongo González. Bogotá: En la Frontera, 2017.

PAREDES, Julieta. Hilando Fino. Desde el feminismo comunitario. 2. ed. México: Comunidad Mujeres Creando Comunidad, 2014.

QUIJANO, Aníbal. A Colonialidade do poder, Eurocentrismo e América Latina. In: LANDER, Edgardo (org.). A colonialidade do saber: eurocentrismo e ciências sociais. Buenos Aires: CLACSO, Consejo Latinoamericano de Ciencias Sociales, 2005.

QUIJANO, Aníbal. Colonialidad del poder y clasificación social. In: QUIJANO, Aníbal. Cuestiones y horizontes: de la dependencia histórico-estructural a la colonialidad/ descolonialidad del poder. Buenos Aires: CLACSO, 2014.

MAY, Roy H. Ética y médio ambiente: hacia una vida sostenible. 2. ed. San José, Costa Rica: DEI, 2004.

MIES, María. La necesidad de un nuevo proyecto: el planteamiento de subsistencia. In: MIES, María; SHIVA, Vandana. La praxis del ecofeminismo: biotecnología, consumo, reproducción. Traducción de Mireia Bofill y Daniel Aguilar. Barcelona: Icaria Antrazyt, 1998.

MUNANGA, Kabengele. Rediscutindo a mestiçagem no Brasil: identidade nacional versus identidade negra. Petrópolis, RJ: Vozes, 1999.

MUNANGA, Kabengele. Consideraçôes sobre o debate nacional a respeito do multiculturalismo na escola e das cotas no Ensino Superior. Universidade e Sociedade Brasília, v. XX, p. 35-44, 2010.

SAID, Edward. Orientalismo: o Oriente como invenção do Ocidente. Tradução de Tomás Rosa Bueno. São Paulo: Companhia das Letras, 1990.

SCHWARCZ, Lilia Moritz. O espetáculo das raças: cientistas, instituições e questão racial no Brasil. 1870-1930. São Paulo: Companhia das Letras, 1993. 
SCHWARCZ, Lilia Moritz. Racismo no Brasil. 2. ed. São Paulo: Publifolha, 2013.

SEGATO, Rita Laura. Gênero e colonialidade: em busca de chaves de leitura e de um vocabulário estratégico descolonial. E-cadernos, CES, v. 18, 2012.

SHIVA, Vandana. Monoculturas da mente: perspectivas da biodiversidade e da biotecnologia. São Paulo: Gaia, 2003.

TAYLOR, Charles et al. Multiculturalismo: examinando a política de reconhecimento. Tradução de Marta Machado. Lisboa: Instituto Piaget, 1998.

TODOROV, Tzvetan. A conquista da América: a questão do outro. Tradução de Beatriz Perrone Moi. São Paulo: Martins Fontes, 2010.

WIEVIORKA, Michel. Será que o multiculturalismo é a resposta? Educação, Sociedade e Culturas, n.12, p. 7-46, 1999.

ZEA, Leopoldo. Discurso desde a marginalização e a barbárie. Tradução de Luis Gonzalo Acosta Espejo e Maurício Delamro. Rio de Janeiro: Garamond, 2005.

Recebido: $14 / 8 / 2020$

Aceito: 28/01/2021 
CARVALHO, G. P. 